\section{SP0140 PATIENT ENGAGEMENT IN RESEARCH: A PCORI EXEMPLAR}

J. Poole. Occupational Therapy Program, University of New Mexico, Albuquerque, United States

This session will discuss patient and stakeholder involvement as members of the research team on a grant funded by the Patient Centered Outcomes Research Institute (PCORI). Patients with a rare chronic disease, systemic sclerosis, and members from key stakeholder organizations were involved in evaluating, revising and testing the effectiveness of an internet self-management program. They participated at several levels of engagement including planning the study, conducting the study, and disseminating the results. This session will discuss how engagement occurred at each of these levels through different opportunities such as creating interventions, identifying outcomes, recruiting, presenting findings, and planning dissemination efforts. The benefits and challenges for both researchers and patient research partners will also be described.

Disclosure of Interest: None declared

DOI: 10.1136/annrheumdis-2017-eular.7294

FRIDAY, 16 JUNE 2017

RA treatment in patients wanting to become pregnant - interactive session

\section{SP0141 NEW RA, BUT WHAT ABOUT A NEW BABY?}

\section{A. Willemze. Rheumatology, LUMC, Leiden, Netherlands}

Rheumatoid arthritis (RA) is a chronic inflammatory autoimmune disease affecting women often in their childbearing years. In this case presentation a 35 year old female patient is illustrated with a recently diagnosed rheumatoid arthritis with active disease and a wish to conceive in the nearby future. Management of disease activity in patients who wish to conceive or during pregnancy might be a challenge due to limited treatment options. How should we treat this patient taking into account her wish to conceive in the nearby future? Should the patient postpone her wish to conceive because of active disease?

Disclosure of Interest: None declared

DOI: 10.1136/annrheumdis-2017-eular.7182

\section{SP0142 FOREPLAY AND FINALE: FACTORS AFFECTING FERTILITY, BIRTH AND LACTATION IN RHEUMATOID ARTHRITIS PATIENTS. CLINICAL CASE}

\section{P. Nero. Rheumatology, Hospital CUF Descobertas, Lisboa, Portugal}

We present the clinical case of a 38 year old woman diagnosed with rheumatoid arthritis at the age of 32 . She went into remission of her disease during treatment with subcutaneous methotrexate ( $25 \mathrm{mg} /$ week) for 2 years. She decided to become pregnant and stoped treatment. RA relapses 4 months later and she has no response to classic DMARD's (sulphassalazine and hydroxychloroquine) and starts etanercept ( $50 \mathrm{mg} /$ week). She gets pregnant and achieves remission at week 16 of her pregnancy. At week 36 she is still in remission and stops etanercept. 2 months after giving birth the disease relapses but she wants to breastfeed and would like to restart etanercept. We agreed and 3 months after restarting anti-TNF RA is again in remission. In January 2017 her RA is inremission for 15 months and keeps her medication with etanercept every other week because she plans another pregnancy.

Disclosure of Interest: None declared

DOI: 10.1136/annrheumdis-2017-eular.7144

\section{FRIDAY, 16 JUNE 2017}

\section{Latest advances in the treatment and management of psoriatic arthritis and the latest news on the use} of Biosimilars in RMDs

\section{SP0143 A NEW DAY FOR PEOPLE WITH PSORIATIC ARTHRITIS: A HETEROGENEOUS DISEASE THAT CAN BE TREATED WELL?}

L.C. Coates. Nuffield Department of Orthopaedics, Rheumatology and Musculoskeletal Sciences, University of Oxford, Oxford, United Kingdom

This talk will summarise recent advances in research around the treatment of psoriatic arthritis (PsA). Firstly there will be an update on research that shows the importance of treating patients promptly when they are diagnosed. Then results from studies of new therapies for both psoriasis and psoriatic arthritis will be shown to highlight the drugs that have recently become available in the clinic or are likely to be become available in the next few years. This will include new biologic disease modifying drugs with different targets including those that target interleukin 17 and interleukin 23 as well as new oral medications that are part of a family called small molecules. The role of these new therapies and how they compare to existing therapies in the clinic will be addressed. Finally there will be a summary on the research of how to use the existing and new therapies in the clinic including the use of the "treat to target" strategy.

Disclosure of Interest: L. Coates Grant/research support from: Abbvie, Janssen, Consultant for: Abbvie, BMS, Celgene, Janssen, Lilly, MSD, Novartis, Pfizer, Sun Pharma, UCB

DOI: 10.1136/annrheumdis-2017-eular.7145

\section{SP0144 BIOSIMILARS IN RHEUMATIC DISEASES: SOCIETY CHANCES VERSUS PATIENT CONCERNS}

\section{A.A. Den Broeder. Rheumatology, St. Maartenskliniek, Ubbergen, Netherlands}

Biosimilars are biologically but also in clinical practice for all intents and purposes identical to the original drug, as has been shown in blinded trials. But the perception amongst patients and sometimes physicians is one of possible inferiority, therefore they are often reluctant to transition to a biosimilar. However, although the listed prices of biosimilars and original products are the same, discounts are often higher for biosimilars, and widespread adoption of biosimilars drives the mean discount opt. So, society, hospitals, insurance companies and governments have preference for introduction of biosimilars to drive costs down. Starting in new patients with a biosimilar is not controversial. Transitioning existing users from originator to biosimilar however is. This field has some interesting aspects, two of which will be elaborated on:

$1 /$ balance of power, interests and ethics: different approaches are used by hospitals, insurance companies and governments to get biosimilars in use (collective buy e.g.). Big pharma are sometimes using campaigns to discredit biosimilars (create FUD, Fear Uncertainty and Doubt) towards patients and doctors, although some pharmaceutical companies are making original biologicals as well as biosimilars. Scientific societies of doctors have different recommendations, based on different beliefs towards biosimilars. In Most countries, Patients freedom of choice and right for best care are seen as paramount, but the other side of the coin might be that patients can be asked to adhere to a "social contract" to help in making healthcare financially sustainable for all.

2/ nocebo and attribution in open label transitioning: blinded research has shown that tansitioning to a biosimilar is not different with regard to safety and effect than continuing the original biological. However, in clinical practice a patient and physician knows that the patient has changed to a biosimilar. This may lead to nocebo effects (due to the perceived inferiority of the drug, experiences of subjective adverse effects and loss of efficacy are induced). In addition, adverse events of loss of efficacy that occurs independent of drug switch might be attributed to the biosimilar, called incorrect causal attribution. Both effects lead to more patient stopping a biosimilar after unblinded switch than in blinded studies. Prevention of nocebo and attribution in daily care is perhaps possible using a variety of techniques (e.g. restriction of fall back to originator, $n=1$ blinded provocation test, biobetter communication, patient incentive, patient/physician education), but this requires more research.

In summary, the use of biosimilars is a chance for society to maintain healthcare affordable, but it represents a challenge to maximise this potential.

Disclosure of Interest: None declared

DOI: 10.1136/annrheumdis-2017-eular.7222

\section{FRIDAY, 16 JUNE 2017}

From pre-RA to established RA

\section{SP0145 PATHOPHYSIOLOGIC PROCESSES LEADING TO THE DEVELOPMENT OF AUTOIMMUNITY}

\section{R. Toes. Rheumatology, Leiden University Medical center, -Leiden, Netherlands}

Rheumatoid arthritis (RA) is a common complex disease characterized by chronic inflammation which results in joint destruction and significant disability in those affected. According to the World Health Organisation, within 10 years of onset, at least $50 \%$ of patients in western countries are unable to sustain a full-time job bringing about detrimental consequences to patients as well as exorbitant societal costs. The cause of RA remains unknown. Human genetic studies have provided valuable insight with over 100 genetic risk factors identified to date. Genetic variants at the human leucocyte antigen (HLA) locus remain the most prominent genetic risk factor. Smoking is the best known environmental factor to date. Microbial triggers have also long been postulated in RA although specific microbes involved in disease pathogenesis remain to be identified.

The majority of RA patients (60-70\%) harbors autoantibodies, including Rheumatoid factors (RF) and autoantibodies against modified self-antigens, commonly termed Anti-Modified Protein Antibodies (AMPA). A prominent example of AMPA are Anti-Citrullinated Protein Antibodies (ACPA). ACPA are highly disease-specific biomarkers of important diagnostic and prognostic value, with ACPA-positive patients being at risk for rapidly progressive, destructive and systemic disease. The strongest genetic risk factors for RA, the so-called HLA-shared epitope (SE) alleles, associate only with ACPA-positive-disease, indicating that ACPA define a specific disease entity within the complex group of symptoms clinically defined as RA. Current concepts of RA pathogenesis hold that a sequence of events leads to the development of ACPA-positive disease. Environmental factors are thought to cause an initial break of tolerance leading to the generation 